\title{
Incidence of leukaemia and lymphoma in young people in the vicinity of the petrochemical plant at Baglan Bay, South Wales, 1974 to 1991
}

\author{
R A Lyons, S P Monaghan, M Heaven, B N C Littlepage, T J Vincent, G J Draper
}

\begin{abstract}
Objective-To determine whether there was an increased incidence of leukaemias and lymphomas in young people aged less than 25 years in the locality of a petrochemical plant at Baglan Bay, South Wales.

Methods-Geographical population based study to compare the observed and expected incidence of leukaemia and lymphoma with onset before the age of 25 , in the years 1974 to 1991 . The population was aged 0-24 years and lived within 1.5 and $3 \mathrm{~km}$ of the plant. The observed number of cases in various categories were compared with the expected numbers of cases calculated from the Welsh cancer registration rates.

Results-Although the observed numbers were generally greater than would be expected, none of the comparisons showed significant excess of leukaemias or lymphomas for any period of years. Conclusions-The study shows that the incidence of leukaemias and lymphomas in children and young people in the area around the BP Chemical site at Baglan Bay, South Wales, between the years 1974 and 1991 was not significantly greater than normal.
\end{abstract}

(Occup Environ Med 1995;52:225-228)

Keywords: petrochemicals, leukaemia, lymphoma, children

Over several years, concern has been expressed by local people that the incidence of cancer in the Sandfields area of Port Talbot and around the BP Chemical site at Baglan Bay was higher than normal. In particular, concern was expressed about the number of cases of leukaemia and lymphoma in children and young adults in the area.

The petrochemical plant, the site of which is adjacent to a large council estate, opened in 1963, although similar industrial processes had been in operation there since the middle 1950 s. A major expansion of the plant took place in 1972, and throughout its life it has produced chain hydrocarbons including ethylene, cyclic hydrocarbons including benzene, polymers such as polyvinyl chlorides, and ethanol. Airborne byproducts are emitted to the atmosphere through a tall stack and excess heat is dissipated as steam through neighbouring cooling towers after generating electricity. Any build up of high pressures in the system is controlled by intermittently burning off gases at two tall flare stacks. This produces considerable light and noise.

Another local source of atmospheric pollutants is the main South Wales transport corridor comprising the M4 motorway and the main line diesel powered railway, both of which are a short distance inland from the plant and run through densely populated areas.

The incidence of childhood cancers in the area was investigated by the Welsh Cancer Registry in 1989. No significant excess of cancers was found (personal communication), but because of continuing local concern the matter was referred to the small area health statistics unit (SAHSU), at the London School of Hygiene and Tropical Medicine. More recently, a television company became interested in the issue and intended to broadcast a programme on the results of an investigation it had carried out.

Communication between one of the authors (RAL) and the programme producer showed that the investigation carried out by the television company seemed to show a significant excess of leukaemias and lymphomas in young people in the vicinity of the plant. A programme based on these results would be likely to cause considerable anxiety to the population living in the vicinity of the plant as well as to relatives of those who had died. Given that the intended date of broadcast was imminent and that the results of the SAHSU study $^{1}$ would not be available for several months, it was decided to check the accuracy of the television company's claims by carrying out a local investigation with similar methods.

\section{Method}

The television company's investigation was based around the rates of leukaemias and lymphomas (coded with the ninth revision of the International Classification of Diseases, ICD-9 codes 200-208) occurring within 1.5 and 3 kilometres of the centre of the plant between the years 1974 and 1986. It was not possible to discover why circles of radii 1.5 and $3 \mathrm{~km}$ had been chosen nor why Hodgkin's disease (ICD-9 201) was included with leukaemia and non-Hodgkin's lymphomas. It was decided to follow this plan of analysis so that the accuracy of the television company's claims could be verified. Because the Welsh Cancer Registry was able to provide incidence data up to the end of 1991 , the period 1987 to 1991 was included in our study as well as the 
The study area. $(E D=$ enumeration district).

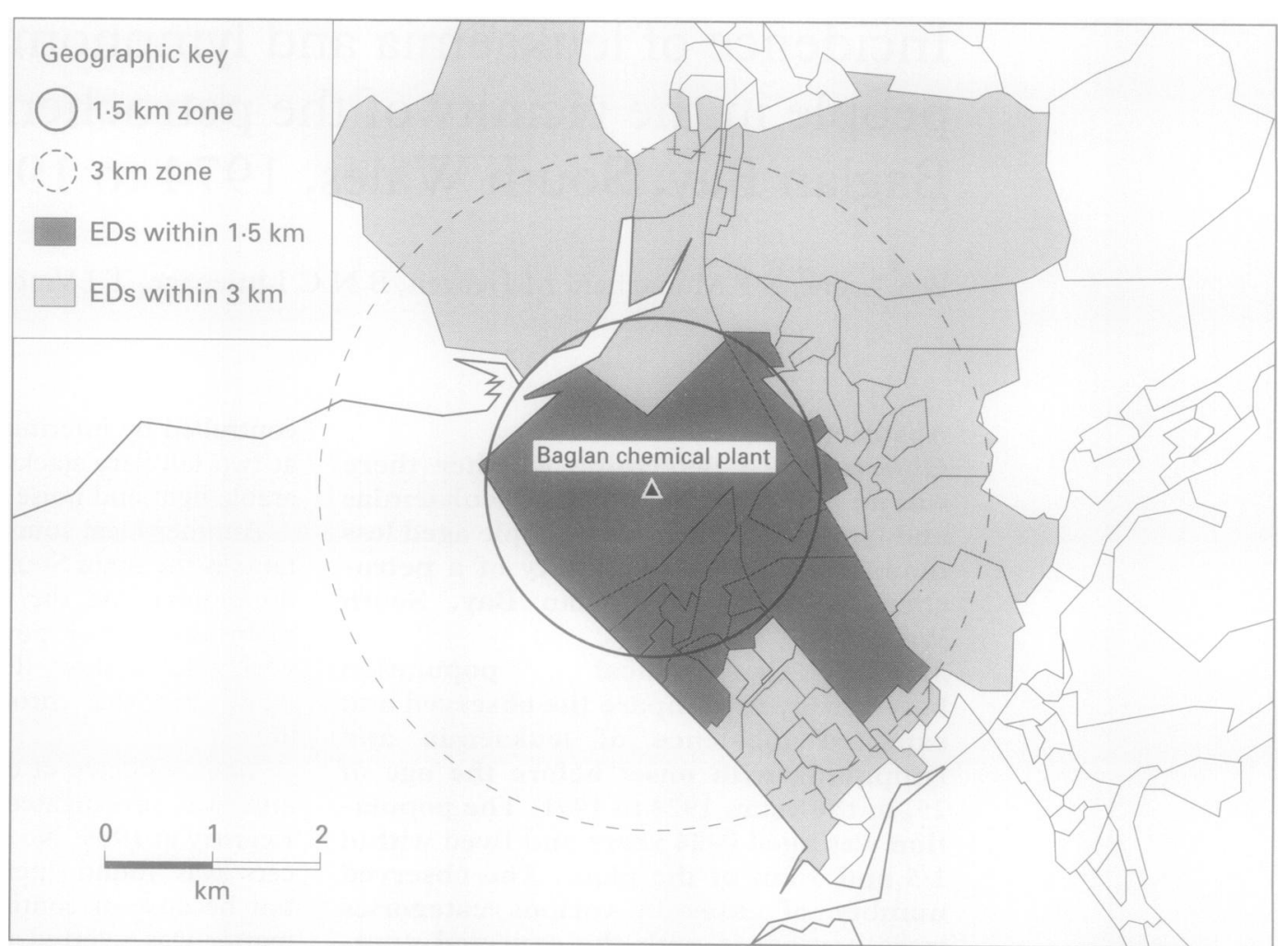

1974 to 1986 period to boost the statistical power of the study and to enhance the relevance of the study in answering local concerns.

To determine whether there was an increase in leukaemias and lymphomas in young people in the area around the chemical site, the observed numbers of such cancers were compared with the numbers that would have been expected on the basis of Welsh cancer registration rates. Thus, cases of leukaemia or lymphoma (ICD-9 codes 200-208) with onset under the age of 25 years observed within the years 1974 to 1991 were identified from the Welsh Cancer Registry, and their frequency was compared with the number that would have been expected if the "all Wales" incidence had applied to the at risk population in question.

Two circles were drawn around a central point of the plant (grid reference 735920 ), the first with a radius of $1.5 \mathrm{~km}$ and the second with a radius of $3 \mathrm{~km}$. Each enumeration district wholly or substantially (greater than $25 \%$ of the area of the enumeration district, and containing housing) within each circle was identified from 1971, 1981, and 1991 enumeration district maps. For these years the populations of those aggregated enumeration districts were obtained from the relevant censuses and the estimates for the intervening years obtained by linear interpolation. The figure shows the relation between enumeration district boundaries, inclusion within the inner and outer circles, and exact $1.5 \mathrm{~km}$ and $3.0 \mathrm{~km}$ distances from the centre of the plant.

The expected numbers of cases for each of the years 1974 to 1991 , separately by sex and five year age groups, were obtained by multi- plying the relevant aggregated population by the "all Wales" incidence for cancers with ICD-9 codes 200-208. The age-sex-year specific expectations were then combined to give overall expected numbers of cases for age groups $0-14$ and $0-24$ for the whole study period for the populations corresponding to the $1.5 \mathrm{~km}$ and $3 \mathrm{~km}$ radius circles.

The observed numbers of cases diagnosed in the defined areas were obtained from a list of all cancers occurring in people aged 0-24 years and resident in West Glamorgan compiled by the Welsh Cancer Registry. Those with addresses and postcodes in the Port Talbot and Neath areas were checked against information held by the National Registry of Childhood Tumours maintained by the Childhood Cancer Research Group at Oxford, and that held by the Leukaemia Research Fund Centre for Clinical Epidemiology in Leeds. Cases not confirmed by these sources were investigated by checking the original hospital notes. The cases were plotted on a large scale map and those within the relevant enumeration districts identified.

\section{ANALYSIS}

Separate analyses were carried out for all leukaemias and lymphomas (ICD-9 200208), all leukaemias and lymphomas omitting Hodgkin's disease (ICD-9 201), and for myeloid leukaemias (ICD-9 205).

As the numbers of cases for any specific age group or sex were very small, the final analyses were carried out on people aged 0-14 years and 0-24 years, living within $0-1.5 \mathrm{~km}$ and $0-3.0 \mathrm{~km}$ of the centre of the plant. Given the number of cases expected, the probability of the observed number or more occurring by 
chance was calculated with the Poisson distribution, to assess the statistical significance of any apparent increase in rates.

\section{Results}

From the initial list of cases for the years 1974 to 1991 produced by the Welsh Cancer Registry, there seemed to be eight cases within the inner circle and an additional 10 cases within the outer circle.

A review of the original medical records and addresses of these cases identified errors in five of them, and the final corrected list contained five cases within the inner circle and an additional eight in the outer circle. Two of the initial cases did not have cancer; one was initially diagnosed as having a lymphoma but further tests showed an inflammatory infiltrate, and the revised diagnosis was not communicated to the Welsh Cancer Registry; the other child never had cancer and the error was due to a wrong code being applied to a surgical procedure in the $1970 \mathrm{~s}$. A further three of the initial cases had address errors which meant that at the time of registration their addresses were outside the outer circle but still within the general Port Talbot area. The accuracy of the addresses in 13

Table 1 Profile of cases

\begin{tabular}{llcll}
\hline $\begin{array}{l}\text { Distance from } \\
\text { plant centre }(\mathrm{km})\end{array}$ & Sex & Age $(y)$ & $\begin{array}{l}\text { Year } \\
\text { registered }\end{array}$ & $\begin{array}{l}\text { ICD-9 } \\
\text { code }\end{array}$ \\
\hline 1.12 & F & 2 & 1988 & 2028 \\
1.15 & M & 10 & 1978 & 2040 \\
1.00 & M & 11 & 1980 & 2019 \\
1.11 & F & 17 & 1985 & 2019 \\
1.38 & M & 12 & 1979 & 2040 \\
2.60 & M & 16 & 1989 & 2050 \\
1.77 & M & 9 & 1976 & 2040 \\
2.55 & F & 14 & 1975 & 2019 \\
1.92 & F & 16 & 1974 & 2050 \\
2.82 & M & 18 & 1980 & 2023 \\
2.63 & F & 2 & 1978 & 2029 \\
$2 \cdot 25$ & M & 4 & 1983 & 2040 \\
2.00 & & & & 2050 \\
\hline
\end{tabular}

Table 2 Observed and expected cases of leukaemias and lymphomas in children 0-14 years old

\begin{tabular}{lllll}
\hline $\begin{array}{l}\text { ICD-9 } \\
\text { code }\end{array}$ & $\begin{array}{l}\text { Area radius } \\
(\mathrm{km})\end{array}$ & $\begin{array}{l}\text { Observed } \\
(\mathrm{n})\end{array}$ & $\begin{array}{l}\text { Expected } \\
(\mathrm{n})\end{array}$ & $\begin{array}{l}P \\
\text { value }\end{array}$ \\
\hline $200-208$ & 1.5 & 4 & 1.790 & 0.11 \\
205 & 1.5 & 0 & 0.198 & 1 \\
$200-208$ & & & & \\
$\quad$ (omitting 201) & 1.5 & 3 & 1.564 & 0.21 \\
$200-208$ & 3.0 & 8 & 5.313 & 0.17 \\
205 & 3.0 & 1 & 0.597 & 0.45 \\
$200-208$ & & & 4.662 & 0.32 \\
\hline
\end{tabular}

Table 3 Observed and expected cases of leukaemias and lymphomas in people 0-24 years old

\begin{tabular}{lllcl}
\hline $\begin{array}{l}\text { ICD-9 } \\
\text { code }\end{array}$ & $\begin{array}{l}\text { Area radius } \\
(\mathrm{km})\end{array}$ & $\begin{array}{l}\text { Observed } \\
(n)\end{array}$ & $\begin{array}{l}\text { Expected } \\
(n)\end{array}$ & $\begin{array}{l}P \\
\text { value }\end{array}$ \\
\hline $200-208$ & 1.5 & 5 & 3.631 & 0.30 \\
205 & 1.5 & 0 & 0.522 & 1 \\
$200-208$ & & & & \\
$\quad$ (omitting 201) & 1.5 & 3 & 2.587 & 0.48 \\
$200-208$ & 3.0 & 13 & 10.676 & 0.28 \\
205 & 3.0 & 3 & 1.542 & 0.20 \\
$200-208$ & & & & \\
$\quad$ (omitting 201) & 3.0 & 10 & 7.640 & 0.24 \\
\hline
\end{tabular}

other cases in the wider Port Talbot area was also checked and none was found to be within the area of interest. Table 1 shows all the cases eligible for inclusion in the study.

Populations within the $1.5 \mathrm{~km}$ and $3.0 \mathrm{~km}$ circles were estimated from the 1971, 1981, and 1991 censuses. In the 1991 census there were 2632 people aged $0-24$ years in the 16 enumeration districts within the inner circle and 8144 in the 54 enumeration districts within the outer circle.

Tables 2 and 3 show the final comparisons of the observed and expected numbers of cases and the probability of the observed or a greater number occurring by chance. None of the comparisons shows a significant excess of leukaemias or lymphomas in the area although some of the observed numbers are in excess of expectation. It should be emphasised that all of these comparisons are based on subgroups of the 13 eligible cases listed in table 1 .

\section{Discussion}

This study shows that the incidence of leukaemias and lymphomas in children and young people in the area around the BP Chemical site at Baglan Bay, between the years 1974 and 1991, was not significantly greater than normal, although at the upper end of what would reasonably be expected. Analyses of leukaemias and related conditions generally exclude Hodgkin's disease. When Hodgkin's disease is excluded from our data the incidence of leukaemias and related conditions moves closer to the expected figure.

Occupational exposure to benzene has been shown to be associated with higher rates of a variety of types of leukaemia, but particularly myeloid leukaemia in chemical workers. ${ }^{2-7}$ Three of the 13 cases in this study had acute myeloid leukaemia; in a group of 13 haemopoetic tumours we would expect two to be myeloid leukaemias. From table 3, based on very small numbers, there is an excess of myeloid leukaemia but this is not significant.

Data from monitoring of benzene concentrations around the site provided by BP and Port Talbot Borough Council (personal communication) indicate that the concentrations are generally low with monthly peak values varying from 4-16 ppb, well below the United Kingdom accepted environmentally safe level of $167 \mathrm{ppb}$, and of similar magnitude to the new proposed limit of $5 \mathrm{ppb} .{ }^{8}$ Rinsky et al estimated that a time weighted exposure to 100 $\mathrm{ppb}$ of benzene for 40 years would be required to produce a $5 \%$ increased risk of leukaemia in an occupationally exposed population. ${ }^{6}$ Although the risks of childhood exposure are currently unknown and may be somewhat different from occupationally exposed adults, the concentrations of benzene in the air around the chemical plant at Baglan Bay would seem to be so low as to be unlikely to cause a measurable increase in leukaemias and lymphomas in children and young people in the area.

This is the most accurate study of the incidence of leukaemias and lymphomas in the Baglan/Sandfields areas to date, because the 
time period under study is longer than in previous studies and considerable efforts were made to verify all cases of leukaemia and lymphoma in the area. If this verification had not taken place and the errors in the data had remained, the results would have indicated a significantly increased incidence of such cancers around the plant. This indicates the particular importance, in studies involving small numbers of cases, of careful checking of the cancer registry data to verify the quality and completeness of data submitted by participating hospitals.

This analysis depends on a comparison of observed and expected cases from the Welsh Cancer Registry. In the study two out of 16 cases investigated in detail turned out not to have a cancer. Given such a small sample size, it is difficult to say whether this degree of over registration is a true reflection of the accuracy of Welsh Cancer Registry data. In our analysis, we did not adjust the expected numbers accordingly. The $95 \%$ confidence interval for a reduction of $12.5 \%$ based on a sample size of 16 lies between $1.6 \%$ and $38 \%$. If we had reduced the expected values also by $12.5 \%$ the conclusions would not have been changed. For example, within the $1.5 \mathrm{~km}$ circle for ICD-9 codes 200-208 1.566 cases would have been expected against four observed, yielding a $P$ value of 0.074

An alternative method would have been to compare validated observed cases with expected cases obtained from a cancer registry in which all the cases are validated. Such a register is the National Registry of Childhood Tumours. Table 4 compares rates of leukaemias and lymphomas in children aged 0-14 years from the Welsh Cancer Registry and the National Registry of Childhood Tumours for the years 1978-1987 (personal communication). Rates from these registries are almost identical. Hence, the use of the National Registry to derive expected numbers would not have changed the conclusions. For instance, if the expected number of the comparison with the lowest $P$ value (ICD-9 200-208, within $1.5 \mathrm{~km}, 0-14$ years) was based on National Registry rates, the expected number would increase by $4.5 \%$ to 1.874 and the $\mathrm{P}$ value would increase to $0 \cdot 12$.

We have not attempted to adjust the expected values to allow for the socioeconomic status of the area. There is some evidence that the incidence of acute lymphoblastic leukaemia at ages $0-14$ is lower in areas of lower socioeconomic status. ${ }^{9}$ This

Table 4 Comparison of the rates of leukaemias and lymphomas in children aged 0-14 years from the Welsh Cancer Registry (WCR) and from the National Registry of Childhood Tumours (NRCT), for the period 1978-1987

\begin{tabular}{llll}
\hline ICD-9 code & WCR rate & NRCT rate & $\begin{array}{l}\text { WCR ratel } \\
\text { NRCT rate }\end{array}$ \\
\hline $200-208$ & 4.953 & 5.186 & 0.955 \\
205 & 0.673 & 0.637 & 1.057 \\
$200-208$ & & 4.637 & 0.959 \\
\hline
\end{tabular}

effect is, however, small and may not apply to the other diagnostic groups or at ages 15-24. The analyses of the effect of the "deprivation score" referred to in the accompanying paper by Sans $e t a l,{ }^{\prime}$ and particularly of the effect on expectation at ages 0-24 (S Pattenden, personal communication) suggest that the expectations would decrease by less than $5 \%$ if socioeconomic status were taken into account. This would have little effect on the analysis described here: the largest effect in tables 2 and 3 would be that in the first line (cases with ICD-9 codes 200-208, ages 0-14, within $1.5 \mathrm{~km}$ of the plant) the expectation would change to 1.700 and the $P$ value to 0.09 -still non-significant.

It could be argued that it would have been better to have used a boundary free method, such as that of Bithell and Stone, ${ }^{10}$ used in the SAHSU study, ${ }^{1}$ to determine whether there is a relation between cancer incidence and distance from the plant. The purpose of our study was specifically to determine whether there was a significant excess of leukaemias and lymphomas within $1.5 \mathrm{~km}$ and within $3 \mathrm{~km}$ of the plant, as was to be reported in the television programme. The results of this investigation were made available to the television company two days before the programme was scheduled to be screened on national television. The documentary was withdrawn and a potential disaster, in terms of psychological effects on local residents, living cases, their relatives, and those of the deceased, averted.

Although this study differs from the SAHSU study ${ }^{1}$ the use of fixed boundaries rather than boundary free methods, and in examining the period 1974 to 1991 rather than 1974 to 1984 , the results are similar and do not support the hypothesis that rates of leukaemia and lymphoma are higher than average in young people in the vicinity of the $\mathrm{BP}$ petrochemical plant at Baglan Bay.

We acknowledge Dr Mary Cotter and Ms Sue Leakes, Welsh Cancer Registry and Professor Ray Cartwright, Leukaemia Research Fund Centre for Clinical Epidemiology, Leeds.

1 Sans S, Elliott P, Kleinschmidt I, Shaddick G, Pattenden $S$, Walls P, Grundy C, Dolk H. Cancer incidence and mortality near the Baglan Bay petrochemical works, South Wales. Occup Environ Med 1995;52:217-224.

2 Aksoy M, Erdon S, Dincol G. Types of leukaemia in chronic benzene poisoning. A study in thirty four patients. Acta Haematol 1976;55:65-72.

3 Rushton L, Alderson MR. A case control study to investigate the association between exposure to benzene and deaths from leukaemia in oil refinery workers. $\mathrm{Br} f$ Cancer 1981;43:77-84.

4 Arp EW, Wolf PH, Checkoway H. Lymphocytic leukaemia and exposures to benzene and other solvents in the rubber industry. $\mathcal{F}$ Occup Med 1983;25:590-602.

5 Aksoy M. Malignancies due to ocupational exposure to benzene. Am F Ind Med 1985;7:395-402.

6 Rinsky RA, Smith AB, Hornung R, et al. Benzene and leukaemia. An epidemiological risk assessment. $N$ Engl f Med 1987;316:1044-50.

7 Yin SN, Li GL, Tain FD, et al. A retrospective cohort study of leukaemia and other cancers in benzene workers. Environ Health Perspect 1989;82:207-13.

8 Expert Panel on Air Quality Standards. Benzene. London: HMSO, 1994.

9 Draper GJ, ed. The geographical epidemiology of childhood leukaemia and non-Hodgkin's lymphomas in Great Britain leukaemia and non-Hodgkin's lymphomas in Great Britain 1966-83. London: HMSO, 1991.
and population subjects No 53.)

10 Bithell JF, Stone RA. On statistical methods for analysing the geographical distribution of cancer cases near nuclear installations. $\mathcal{f}$ Epidemiol Community Health
1989;43:79-85. 